\title{
The stratified significance of a historic façade as a basis for a more durable conservation approach
}

\author{
Nathalie Van Roy ${ }^{a}$, Koenraad Van Balen ${ }^{a, b}$, Els Verstrynge ${ }^{c}$, Silvia Naldini ${ }^{d}$ \\ a KU Leuven, Civil Engineering Department, Kasteelpark Arenberg 40, Bus 2448, B-3001 Heverlee, Belgium \\ ${ }^{b}$ KU Leuven, Raymond Lemaire International Centre for Conservation (RLICC), Kasteelpark Arenberg 1, B-3001 Heverlee, Belgium \\ ' KU Leuven, Department of Architecture, Campus Sint-Lucas Brussels and Ghent, Paleizenstraat 65-67, B-1030 Schaarbeek, \\ Belgium \\ d Delft University of Technology, Faculty of Architecture, P.O. Box 5043, 2600 GA Delft, The Netherlands
}

This is the preprint of a paper published as: Van Roy, N., Van Balen, K., Verstrynge, E., Naldini, S. (2015). The Stratified Significance of a Historic Façade as a Basis for a more Durable Conservation Approach. International Journal for Restoration of Buildings and Monuments, 21 (4-6), 137-148: 2015.

Original paper DOI: 10.1515/rbm-2015-1004

\begin{abstract}
In heritage conservation, a gap is often observed between the theory of conservation as a durable process that aims at the preservation of a historic building and the practice of restoration as a single intervention that aims at a fast and convincing result. This paper describes the proposed approach for the conservation of the main façade of the Shoemakers Chapel (in Dutch: Schoenmakerskapel) in Antwerp (Belgium), a listed monument since 1976. It serves as an example of how to develop a durable and realistic approach for the conservation of a $16^{\text {th }}$ century façade. The basis for the conservation approach is the understanding that each intervention should take the stratified significance of the historic façade into account. In this paper, it will be shown how to combine a study of the façade from a technical point of view with an analysis of the façade as a carrier of cultural significance.
\end{abstract}

\section{Introduction}

The $16^{\text {th }}$ century Shoemakers Chapel is situated in the historic centre of Antwerp (Belgium). Its main façade, the subject of this paper, experienced several interventions over time (fig 1). Originally the chapel's façade was in brick and natural stone. Historic pictures from the end of the $19^{\text {th }}$ century demonstrate that the façade was finished with a plaster. This plaster was removed during a restoration that took place in 1925. The brickwork was left unprotected and its surface was rough, which was defined as "eroded". However, the roughness of the brickwork could be the effect of a sandblast cleaning intervention that took place in the 1980's, as shown on a picture that was found in the archives of the Flemish Heritage Agency. The erosion of the brickwork was the main reason for administrators to commence the search for a conservation approach. This article reports the development of this approach and demonstrates how the stratified significance 
of the façade can form the basis for a durable conservation. It therefore demonstrates in practice how the concept of preventive conservation as a durable process that aims at the preservation of a historic façade can be put into practice [1-3].

This article firstly reports the investigation of the current state of the main façade of the Shoemakers Chapel. Taking into account the complexity of the conservation of a historical façade and its stratified significance, a distinction is made between the technical investigation of the façade and the assessment of its cultural significance.

The report of the preliminary survey clearly shows how a step by step method was applied to gradually obtain insights in the building materials, their characteristics and their state of conservation. The influence of environmental conditions is studied, as well as the functioning of the façade as part of the drainage system. The characteristics and state of conservation of the materials are assessed, based on a detailed visual inspection and a limited number of non-invasive testing. All this information together leads to an assessment of the existing deterioration processes. The assessment of the cultural significance firstly consists of a thorough analysis of the façade's history, by interpreting historic traces using the method of stratigraphic survey. Hereafter, social and aesthetic values are assessed through an analysis of the perception of the façade as the face of the building and as part of the historic landscape in which it is embedded.

The second part of the article demonstrates how a thorough understanding of the stratified significance of the façade can form the basis for a durable conservation approach. The detailed technical investigation of the main façade results in an assessment of deterioration processes. A clear understanding of the cultural significance determines the limits of possible interventions. Therefore, this systematic approach gradually leads to a conservation recommendation that takes into account the complexity of the historic façade. The case clearly demonstrates the shift from an intrusive restoration procedure to the concept of preventive conservation.

\section{The stratified significances of a historic façade}

The façade is the most representative part of the building envelope. Throughout history, the building envelope has fulfilled different functions, that can be categorised as protection (from rain, cold/heat, wind, frost, sun radiation, intrusions), comfort (light, ventilation, insulation) and representation (decorations, dimensions, use of precious materials) [4, 5].

A historic façade, being also the "face" of the building, fulfils thus both a technical and an aesthetic role. As the bearer of numerous historic layers, it is also a historic reference, not only of the building's history as such, but also of the history of the applied building materials and techniques, and of the history of restoration practice.

\subsection{Investigation of the façade from a building-technical point of view}

The required technical performance of the building envelope stems from the building's function and use. The technical performance of an existing façade is based on the applied building materials, their characteristics, their state of conservation and the composition of the wall, as well as the connections between different materials and building components. Since historic façades are 
often the result of numerous interventions and alterations, their composition could be complex and the applied materials could be diverse. It is therefore important to invest in understanding the façade's history, its composition, its functioning and the materials of which it is composed, before any intervention can be executed, in order to clearly understand the technical impact of this intervention.

For the case of the Shoemakers Chapel, the building-technical investigation consisted of an onsite survey on three levels: the urban setting, the façade and the materials. Firstly, the environmental conditions were studied to understand their potential influence on the state of conservation of the materials. Secondly, the functioning of the façade as part of the drainage system was analysed. Thirdly, the applied materials were characterised and their state of conservation was determined. Finally, four deterioration processes were assessed, based on the data collected from the multi-level survey.

\subsubsection{The influence of environmental conditions}

In order to understand the potential influence of the environmental conditions on the state of conservation of the materials, it is important to examine the geographical location of the building, the orientation of the façade, the traffic density in nearby streets, the dimensions of the streets, the heights and densities of the surrounding built environment.

The Shoemakers Chapel is located in the historic centre of Antwerp, along a major street (20 meters width between façades) with a high traffic density (cars, busses, trams). The introduction of high rise buildings during the twentieth century across the street has transformed the built environment of the chapel. A study of Historic Scotland [6] revealed a clear impact of high rise buildings on the soiling of existing historic buildings. The study indicated that due to wind circulation patterns surrounding the high rise buildings, the lower historic buildings facing them presented a larger amount of soiling. These aspects should therefore be taken into account when interpreting the results of the investigations on the materials. The examining of the air quality data for Antwerp's city centre, January - February 2012, a cold period, shows that the European limiting values for the concentration of air pollutants are only exceeded for particulate matter (PM) and not for sulphur dioxide $\left(\mathrm{SO}_{2}\right)$ and nitrogen dioxide $\left(\mathrm{NO}_{2}\right)$ (table 1). The levels of sulphur dioxide $\left(\mathrm{SO}_{2}\right)$ are even negligible. This indicates that the present air quality will probably only cause the deposit of particulate matter, resulting in soiling, but not the chemical deterioration phenomena that are often caused by sulphur dioxide $\left(\mathrm{SO}_{2}\right)$.

\subsubsection{The functioning of the façade as part of the drainage system}

The façade of a building takes part in water drainage in three ways: firstly, it is the main support for the drainage pipes that lead water from the roof to the sewer system or rain water collection units; secondly, it conducts rain water flowing over its surface to street level; thirdly, it absorbs part of the rain water and releases it over time when drying.

Studying the functioning of the façade as part of the drainage system meant verifying the state of conservation of the principle elements (gutters, drainage pipes, windowsills, plinths, ...).

For the Shoemakers Chapel, the state of conservation of the drainpipes was rather good, but the connections between the gutter and the vertical drainpipes was a delicate point where water 
infiltrations were very likely (fig 2). A proposal was made to attach the vertical drainpipe to the gutter and prevent the infiltration of rain water into the façade. It would be sufficient to introduce an end piece in metal that covers the hole and guarantees a smooth connection with the gutter.

Rain water that runs down the façade passes at the very top part of the façade a cove in natural lime stone, that is rather well conserved. Most of the elements have maintained their functional form, so that the water can be conducted to the lower parts of the façade. The next important passage for the rain are the windowsills in natural lime stone. In most places they were covered with moss. Near the stained glass windows, repairs were visible in cement mortar (fig. 3). Some elements were also strongly deteriorated (fig. 4) and were therefore no longer capable to fulfil their function. Some of them will need repairs with adapted and compatible repair materials, others should be replaced with new elements. At last the lower part of the façade, the plinth in different types of natural stone (see 2.1.3) locally showed grow of moss, which indicates a problem of local stagnation of water.

\subsubsection{Characterising the applied materials and determining their state of conservation}

The characterisation of the applied materials was performed at two levels of detail. A more general assessment of the entire façade included the categories of materials and the general state of conservation (fig 5). A more in-depth investigation of certain areas of the façade allowed for a more detailed determination of the applied materials, the sizes of the elements, the workmanship details and specific alterations (fig 6).

For the in-depth survey, a regular raster of 1 meter by 1 meter was applied to divide the façade into segments or inspection areas. Ten interesting areas were selected, based on a combination of the following selection criteria:

1. areas where alterations were recorded during the general assessment of the state of conservation of the façade;

2. areas where different building components meet;

3. areas with high environmental exposure, such as the connections with gutters and windowsills or the plinth;

4. areas where different materials meet;

5. areas with historic traces;

6. areas showing a seemingly good state of conservation (for the assessment of the material characteristics).

The investigation of the selected inspection areas included a visual inspection and on-site noninvasive testing. Observations were noted in standard survey sheets, with a slight difference between the observed characteristics for bricks and natural stones (fig 7 and 8). Mortar was considered as a material connected to the surrounding bricks or natural stone. The schemes for on-site visual inspection were developed based on a literature study of the main characteristics of bricks and natural stone. 
It is important, during a first visual inspection of the brick, to record geometry, colour, density, cohesion, surface appearance, and details concerning manufacturing and state of conservation [79]. These characteristics will contribute to understand chronological phases, to assess the state of conservation and to evaluate the impact of a planned intervention. The description of the detected alterations for bricks is based on Italian standard UNI 11182 and the damage atlas of the Masonry Damage Diagnostic System (MDDS) $[10,11]$. An alteration is considered a change of the material's characteristics that does not necessarily imply the worsening of its characteristics in relation to its future conservation. A degradation or damage is considered an alteration that does imply the worsening of the material's characteristics, putting at risk its future conservation. This distinction in terminology, that takes into account the severity of the alteration and the risk for the material's future conservation, is based on the Italian standard.

The visual inspection and measurement of the bricks allowed to recognize three different types of bricks (fig. 6). The first type is the most occurring (type 1, fig. 6): it is a handmade brick of a dark red colour and an average size of $17 \mathrm{~cm}$ (length) by $4 \mathrm{~cm}$ (height). The second brick was found around the oculi (type 2, fig. 6). The brick has an orange colour, is also handmade and of similar size. The third type of brick (type 3, fig. 6) was found locally, for example near the scaffolding holes. It is a very thin, orange brick that looks like terracotta. It was used to fill holes in places were elements were inserted when the spaces were too large to be merely filled with mortar. In fig. 6 some of these bricks can be seen around the key stone in natural limestone and below the lintel in natural limestone.

The state of conservation of the bricks was generally good. A superficial deposit was found on most of the bricks, as well as signs of erosion.

A literature study on the classification of natural stones and their main characteristics indicated that it is important, to record data on the stone hardness, degree of compactness, colour and the presence of traces of traditional stone carving techniques [8, 9, 12]. These characteristics contribute to the identification of the types of natural stone applied, the assessment of their state of conservation and allow to plan interventions.

Three types of natural lime stones were recognised within the façade of the Chapel: Lede stone, a local limestone, Gobertange, a local limestone, and Savonnières, a French limestone. Lede stone is a sandy limestone with a compressive strength between 55,7 and $122,5 \mathrm{~N} / \mathrm{mm}^{2}$ and an average compressive strength of $82,6 \mathrm{~N} / \mathrm{mm}^{2}$ [13]. Although the individual elements are mostly of a homogeneous structure, different qualities can be found within the quarry. Lede stone has been used for numerous historic buildings in Flanders and in the Netherlands. The stone blocks were transported over the rivers Dender and Schelde and even over the North Sea to the upper north part of Holland [12]. From the $19^{\text {th }}$ century onward, Gobertange was often used as a replacement stone for Lede stone. Gobertange is a limestone that was extracted around a town called Gobertange (region Tienen - Geldenaken) [12]. For the main façade, the stone was used mostly in the plinth area, possibly as a replacement stone. After 1860, in Belgium and the Netherlands, French limestone was often used for restoration projects. Savonnières is a French limestone, soft, white and rather porous [12]. For the main façade of the Shoemakers Chapel, this stone was used for the scaffold holes and for the lintels of an entrance to the cellar.

In general, the state of conservation of most of the stone elements was quite good. Some showed a superficial deposit of dust and patina. The Lede stone, showed locally gypsum crusts 
(mainly at the dormer door and window frames on the ground floor), and crumbling, at some exposed locations.

The visual aspect of the pointing mortar, its application, colour, cohesion and finishing type [8] can help to pointing at the differences between pointing types within one façade or building. Furthermore, the visual inspection contributes to the assessment of its state of conservation. For the façade of the Shoemakers Chapel, the pointing mortar was in most cases inaccurately applied, possibly in a recent intervention. It seems that the mortar was spread over an existing mortar that needed repair. Signs of small cracks were detected, which pointed at the need of further analysis. At some places, detachment of the pointing mortar was detected and the underlying lime-based bedding mortar showed crumbling.

After this first visual inspection, which already produced insights in the characteristics and the state of conservation of the applied materials, additional non-invasive testing was performed.

A non-destructive in situ test was done using the Schmidt Pointing Hardness Tester [14] to assess the quality of the mortar. The hardness of the pointing mortar was classified in class $\mathrm{C}$ with an average hardness between 35 and 45, which is too hard for a traditional lime-based mortar. Combining this information with the visual inspection, it was clear that the pointing mortar is cement based.

Two tests were performed for the quantification of the absorption behaviour of the bricks: the Karsten tube penetration test and a gravimetrical test on powder samples for moisture content determination.

The water absorption of the most used type of brick and natural stone (Lede stone) was tested on site using the Karsten tube penetration test [15]. The brick absorbed $4 \mathrm{ml}$ of water during the first 5 minutes. After 15 minutes, another $6 \mathrm{ml}$ of water was absorbed, resulting in a level of water absorption of $0,6 \mathrm{ml} / \mathrm{min}$.

Powder samples of the bricks and mortar were taken at three different depths $(0-1 \mathrm{~cm}, 1-5 \mathrm{~cm}, 5$ $10 \mathrm{~cm}$ ) in order to determine the amount of actual moisture content and the amount of hygroscopic moisture in laboratory. The hygroscopic moisture content of the dried samples was used to assess the presence of soluble salts $[16,17]$. Twenty samples were taken at different heights and for different types of bricks. For all the samples, the amount of moisture and soluble salt - as indicated by actual and hygroscopic moisture content - was negligible [18].

It could be concluded that the tested materials are still in a good condition and may fulfil their role within the construction.

It was a deliberate choice to perform only a limited number of non-invasive tests, that were carefully chosen based on the results of the first visual inspection and provided relevant information

\subsection{4 assessment of the alteration processes}

By combining all the data collected during the on-site survey, four alteration processes could be assessed, using the Masonry Damage Diagnostic System (MDDS) [11]: 
1. an overall soiling of the façade resulting in a rather consistent superficial deposit;

2. the formation of gypsum crusts on the Lede stone

3. the erosion of the bricks;

4. the detachment of the cement-based pointing mortar and the crumbling of the underlying lime-based bedding mortar.

The alteration processes were studied more in detail in order to understand which of them could also be considered processes of degradation. When an alteration is not resulting in a deterioration of a materials characteristics and the conservation of the materials is thus not at risk, this process of alteration should not be considered a process of degradation and an intervention might not even be necessary [10].

\section{Soiling and crust formation}

The first two processes are caused by the environmental conditions. The study of the chapel's environment indicated that the high rise buildings would probably increase the soiling of the façade, an aspect that can be confirmed based on the study of the materials. The measurements of the air quality also demonstrated high levels of particulate matter (PM). This process however will continue and the cause is mostly the traffic density. Although the soiling has an aesthetic impact, it does not cause any deterioration of the materials. It is therefore an alteration which is not a degradation, since the future preservation of the material is not at risk. On the contrary, the gypsum crusts that were found for the Lede stone are a form of chemical transformation. The crusts are the result of higher levels of sulphur dioxide $\left(\mathrm{SO}_{2}\right)$ in the air in the past. Since today the levels of $\mathrm{SO}_{2}$ are negligible, new gypsum crusts will probably not be formed any more.

\section{Erosion of bricks}

The erosion of the bricks can partly be attributed to the environmental conditions, that is to say to the wind circulation created by the high rise buildings in the vicinity. However, it is more likely that the erosion was caused by the removal of the plaster during the restoration of the façade in 1925 , and by the cleaning in the 1980's. Since the cause of the erosion is a previous intervention and there is no evidence that it is progressing, it is considered a non-progressing form of degradation, thus not needing any intervention.

\section{Detachment of pointing mortar}

The detachment of the cement based pointing mortar is due to its incompatibility with the historic masonry and its inaccurate execution. This thin layer of cement-based mortar was simply spread onto the masonry, without even removing or repairing the existing pointing mortar. This careless intervention is however hard to rectify, since the mortar was also partly spread on the bricks. The thin layer of cement based mortar is however prohibiting the underlying lime based mortar to dry properly, which may favour crystallisation and frost damage (crumbling) of the bedding mortar. The cause of these forms of degradation is thus a previous intervention. 


\subsection{The façade as a carrier of cultural significance}

\subsubsection{The façade as a historic reference}

The façade of a historic building is a historic reference and therefore an object of study to understand the building's history, but also the history of the applied materials, techniques, styles, etc. This led historians in the $19^{\text {th }}$ century to oppose against the numerous restoration projects that searched for a unity of style, in a plead for authenticity [19]. The nineteenth century's polemics are however still a question of the day. Even though the concepts of minimal intervention and preventive conservation are imbedded in international charters such as the Venice Charter [20] and the Burra Charter [21], restoration projects today are still too often led by a technical or aesthetical discourse. In order to preserve the very essence of the building's façade, its materials and its historic traces, a thorough understanding of the façade's history is essential and it will contribute to the development of a planned preventive conservation approach that takes into account the importance of the façade as a historic reference [3].

For the interpretation of historic traces in the façade of the Shoemakers Chapel, the method of stratigraphic survey $[22,23]$ was applied. This method is derived from archaeology and has been extended for application on buildings, amongst others, by Mannoni [24, 25]. The analysis starts with a registration of all historic traces, after which the façade is divided into areas, called stratigraphic units (fig. 9). Each stratigraphic unit is part of a single period in time. The analysis is therefore at first reduced to understanding the temporal relation between adjoining stratigraphic units. The relations between the units are represented in a scheme called Harris Matrix (fig. 10), developed by Harris in 1973 for the interpretation of the relation between different stratified layers in archaeology [26]. Without falling back on expensive methods such as carbon dating, mostly, sufficient information is found when the scheme is confronted with other sources, such as historic pictures and plans of interventions, or when the difference in architectural features during historical periods is taken into consideration (chrono-typology).

The history of the main façade of the Shoemakers Chapel consists of three important chronological periods. The first important intervention is the modernisation of the chapel and its façade, probably in the $18^{\text {th }}$ century, with the introduction of oval-formed baroque windows on the second floor (oculi), in the place of larger windows. The second type of brick, of a more orange colour, was then used. The interior of the chapel stems also from this period. During this intervention, the façade was also finished with a plaster layer, which altered its style and aesthetic appreciation. The next important intervention was the restoration of the façade in 1925, when the plaster was removed, the scaffold holes on top were introduced and the dormer window was reconstructed, with the stepped-gable. Finally, archive documents and pictures suggest that there has been a cleaning intervention in the 1980's.

After understanding the complex and stratified history of the chapel's façade, it becomes clear that the façade's current perception is clearly demonstrating the different phases and interventions. 


\subsubsection{The façade as the "face" of a building}

Considering the façade can literally be perceived as the "face" of a building, every intervention will have an impact on the manner in which a building is perceived and experienced.

The social value that is related to the perception of a building could be explained as a relative aesthetic value. This concept should not be mistaken for the absolute aesthetic appreciation, but more as an experience that is related to a single person in a single moment of time, a concept that was first addressed at the beginning of the $19^{\text {th }}$ century and by Riegl was described as "Kunstwollen" $[27,28]$. He considers the modern aesthetic value as a contemporary appreciation, that might change from case to case and from time to time. Maybe this concept will never completely rule out the idea that certain experts can decide on absolute aesthetic values, it indicates however the importance of public participation when an intervention on a historic façade is planned, since it is not always so obvious to understand the perception a larger public has of a building's façade. This was also the case for the Shoemakers Chapel. Whereas the experts were convinced to reintroduce the chapel's $18^{\text {th }}$ century appearance, as a plastered and painted façade in baroque style, the administrators of the chapel were feeling strongly attached to the chapels current appearance. A possible explanation for this contradiction can also be found in the writings of Riegl. He described in his works the importance of the "value of the old" [27]. This is not to be confused with historic value, but it simply explains that people will feel resistant when the natural degradation of a building is interrupted. The fact is that the current state of the façade represents the different stages of the building, its age and everything that has happened to it, often it represents also personal memories.

Apart from the social value attributed to the aesthetic appreciation of the building, it is also important to understand how the façade of a building is communicating with the historic landscape in which it is embedded. A brief study of the evolution of the area surrounding the Shoemakers Chapel indicated that some important events have defined its current appearance. The first important urban intervention was the introduction of the Place Bonaparte (nowadays Groenplaats) in 1815, a large square with trees for which some buildings were demolished. During the First World War, the area surrounding the chapel was almost completely destroyed, and so after the war, around 1930, the year in which Antwerp organised the World Exhibition, the Boerentoren (Peasant's tower) was built, a high rise building of 87 meters and 25 floors, right in front of the chapel. During the Second World War, the area was again gravely damaged due to the explosion of a (V2) bomb in its vicinity [29]. Most interventions however took place on the opposite side of the street, and the current perception of the south side of the Schoenmarkt has not changed that much since the $19^{\text {th }}$ century. Taking this into account, reintroducing the chapel's $18^{\text {th }}$ century appearance and plastering the façade, might restore the dialogue with its neighbours.

\section{A durable conservation approach}

The study of the façade, its materials and their state of conservation demonstrated that two of the assessed alteration processes can be considered ongoing degradation processes: the formation of crusts for the Lede stone and the detachment of the cement-based pointing mortar with crumbling of the lime-based bedding mortar behind. An aesthetic appreciation is given to the 
façade by the chapel's administrators, while experts put forward the option of reintroducing a finishing plaster, both as a protection, and in order to restore the façade's $18^{\text {th }}$ century baroque grandeur. This might also add to the integration of the façade within the existing historical landscape, but it would cancel the final major historic layer, namely the restoration of 1925.

These observations formed the basis for developing a durable conservation approach taking into account the stratified significance of the historic façade. Based on the results of the preliminary studies, four main questions were taken into consideration:

1. How to remove the gypsum crusts?

2. How and when to remove the incompatible cement based pointing mortar?

3. If and when to introduce the plaster?

4. If and how to clean the soiling?

The answers to these questions made up the conservation approach, taking into account that all considered interventions can have five main goals: 1) the consolidation of deteriorated materials, 2) tackling the causes of degradation, 3) decelerating the degradation processes, 4) improving the aesthetic appreciation, 5) monitoring the state of conservation .

\subsection{How to remove the gypsum crusts?}

For the consolidation of the stones with gypsum crusts, two possible approaches were formulated. The first approach, general practice in Flanders, consists of the mechanical removal of the crust and deteriorated material, after which the remaining stone is repaired with a compatible repair mortar, if necessary. The second approach consists of a chemical cleaning with ammonium bicarbonate. Ammonium bicarbonate in watery solutions transforms the calcium sulphate dehydrate into ammonium sulphate, a different type of salt that is however much more soluble in water. By applying the ammonium bicarbonate with poultices, the formed ammonium sulphate will migrate from the stone into the poultices and can be removed from the stone. This is a delicate operation that is not so often applied in Flanders. If it would be chosen, however, the intervention would be limited to a few stones only, and the conservation approach would imply a local application of the chemical cleaning, and less historic material will be lost.

\subsection{How and when to remove the incompatible cement-based pointing mortar?}

The detachment of the cement based pointing mortar and the crumbling of the underlying lime based bedding mortar is caused by the incompatibility of the pointing mortar's physical properties with those of the traditional masonry. It would therefore be advisable to remove this pointing mortar and apply a more compatible lime based pointing mortar after repairing the bedding mortar. However, for those parts where there is no detachment of the pointing mortar, removing it will cause damage to the bricks. Therefore, the state of conservation of the pointing mortar should be assessed on a regular basis and detached cement based pointing mortar should be removed, while locally repairing the bedding mortar and applying a compatible lime-based mortar. 


\subsection{If and when to introduce the plaster?}

At the moment the community of people feeling attached to the chapel are against the application of a plaster to its façade. Technically speaking, the surface can be left unprotected, but its state needs to be monitored.

\subsection{If and how to clean the soiling?}

Some preliminary tests were performed in order to assess the possibility of removing the soiling without causing damage to the historic materials. Three cleaning methods were tried: a steam cleaning, a wet-jet abrasive cleaning and a dry cleansing paste. By means of the steam cleaning method not all the soiling could be removed and due to the high temperatures some historic material was lost (fig. 11, upper part). Applying the wet-jet abrasive cleaning, it was possible to remove all the soiling, even though the materials were clearly affected by the cleaning intervention (loss of surface material, the natural patina) (fig. 11, lower part). The dry cleansing paste was applied with a pencil onto the masonry. It is an industrial product that consists of a self-vulcanizing cleaning paste for the dry removal of the soiling. The paste was left on the surface for two days, but the soiling resulted to be too adherent or too much infiltrated into the pores of the materials to be removed with this technique.

Since it is difficult to remove the soiling without introducing further damage to the already eroded bricks, the conservation approach foresees a regular superficial cleaning of the façade by sponging of the dirt with water.

\section{Conclusions}

By means of a case study, it is shown how the current shift from intrusive restoration towards preventive conservation can have an impact on decisions taken in conservation practice. The adopted methodology is based on the stratified significance of a historic façade.

The conservation approach developed for the façade of the Shoemakers Chapel shows the added value of investing time in understand the building, its environment and materials. It also shows how important it is, from a technical point of view, to look at the façade as a part of the drainage system. The characteristics of the applied materials and their state of conservation were assessed using a two-step method, whereby relevant areas were selected for a detailed survey. This method proved to be practical and useful.

In addition to the building-technical value, the cultural significance of a historic façade was illustrated. To establish the aesthetic appreciation, a dialogue with a large group of people connected with the historic façade proved to be essential. Furthermore, the analysis of the façade's history proved to give clear insights in its history and helped to understand how to preserve the historic reference without losing its authenticity.

Above all, this case demonstrated how a well-considered approach for the conservation of a historic façade can be designed, taking into account the complexity of the problems to be solved and one's responsibility in decision making. 
In practice, however, this conservation approach has been translated into a restoration project that awaits the availability of government funding. In such a government funded restoration project, it is not possible to include the advised monitoring or the long term approach for the repair of the pointing mortar. Alternatives are however available. A new legislation in Flanders encourages owners to develop a management plan for a historic site that indicates a conservation approach over a period of twenty years, which would be the perfect translation of the conservation approach presented in this paper into practice [30].

\section{References}

1. Della Torre, S., Shaping Tools for Built Heritage Conservation: from Architectural Design to Program and Management, in Community involvement in heritage, K. Van Balen and A. Vandesande, Editors. 2015, Garant Uitgevers: Antwerp, Apeldoorn.

2. Forster, A.M. and B. Kayan, Maintenance for historic buildings: A current perspective, Structural Survey, 27(3), pp. 210-229, 2009.

3. Reflections on Preventive Conservation, Maintenance and Monitoring of Monuments and Sites by the PRECOMN OS UNESCO Chair. ACCO, Leuven/Den Haag, 2013.

4. Colomban, M., The wall of the future, in 2nd International Conference on Building Envelope Systems and Technologies1997: Bath.

5. Verhoef, L.G.W., Water - A paradox, the prerequisite of life but the cause of decay, Restoration of Buildings and Monuments, 8(1), 2002.

6. Scotland, H., The consequences of past stonecleaning intervention on future policy and resources, 2003: Edinburgh.

7. Gasparoli, P., Le superfici esterni degli edifici: degradi, criteri di progetto, techniche di manutenzione (E: The façades of buildings: degradations, criteria for projects, techinques for maintenance). Alinea editrice, Firenze, 2009.

8. Musso, S., Recupero e restauro degli edifici storici (E: Repair and restoration of historic building). 2 ed., EPC libri, Roma, 2006.

9. Cagnana, A., Archeologia dei materiali da costruzione (E: Archaeology of construction materials). Editrice Società Archeologica Padana srl, Mantova, 2000.

10. UNI, E.N.I.d.U., UNI 11182 Materiali lapidei naturali ed artificiali. Descrizione della forma di alterazione. Termini e definizioni., 2006, UNI: Milano.

11. Van Hees, R. and S. Naldini, The Masonry Damage Diagnostic System, Restoration of Buildings and Monuments, 1(6), pp. 461-474, 2014.

12. Dreesen, R., M. Dusar, and A. De Naeyer, Natuursteen in Vlaanderen, versteend verleden (E: Natural stone in Flanders, a petrified past). Wolters Kluwer België nv, Mechelen, 2009.

13. Willems, A., V. Cnudde, and G. De Schutter, Ontwikkeling en karakterisering van een mineraal gebonden herstelmortel voor de Ledesteen (E: Development and characterisation of a mineral repair mortar for Ledesteen), in Geologie en bodemkunde2010, Universiteit Gent: Gent.

14. Rilem Tc 127-MS: Tests for masonry materials and structures, Materials and Structures, 30(200), pp. 323-328, 1997. 
15. Hendrickx, R., Using the Karsten tube to estimate water transport parameters of porous building materials, Materials and Structures, 46(8), pp. 1309-1320, 2013.

16. De Witte, E., et al., Final report of EU Project: Evaluation of the performance of surface treatments for the conservation of historic brick masonry, Measurement techniques, 1998.

17. Binda, L., T. Squarcina, and R. Van Hees, Determination of moisture content in masonry materials: calibration of some direct methods, in 8th International Congress on Deterioration and Conservation of Stone1996: Berlin. p. 423-435.

18. Nijland, T.G. and H. Borsje, Oriënterend onderzoek naar de staat van conservering van de gevel van de Schoenmakerskapel te Antwerpen (E: Exporatory examination of the state of conservation of the façade of the Shoemakers Chapel in Antwerp), 2012, TNO: Delft.

19. Ruskin, J., The seven lamps of architecture. John Wiley, New York, 1849.

20. Icomos, International charter for the conservation and restoration of monuments and sites, 1964.

21. Icomos, The Burra Charter, 1999.

22. Boato, A., L'archeologia in architettura: Misurazioni, stratigrafie, datazioni, restauro (E: Archeology in architecture: measurements, stratigraphies, datings, restoration). Marsilio Editori, Venezia, 2008.

23. Doglioni, F., Stratigrafia e restauro, tra conoscenza e conservazione dell'architettura (E: Stratigraphy and restoration, between knwoledge and conservation of architecture). Edizioni Lint, Trieste, 1997.

24. Mannoni, T. and E. Poleggi, Fonti scritte e strutture medievali: problemi di metodo e prospettive di ricerca (E: Written sources and medieval structures: problems in methodology and research possibilities), Archeologia Medievale, I, pp. 171-194, 1974.

25. Mannoni, T., L'analisi delle tecniche murarie medievali en Liguria (E: Analysis of the techniques of medieval walls in Liguria), in Colloquio Internazionale di Archeologia Medievale1976: Palermo. p. 291-300.

26. Harris, E., Principles of archeological stratigraphy. Academic Press, London, 1989.

27. Riegl, A., I/ culto moderno dei monumenti. Vol. 3. Nuova Alfa Editoriale, Bologna, 1903.

28. Pretelli, M., Alois Riegl, in La cultura del restauro, S. Casiello, Editor. 1996, Marsilio Editori: Venezia.

29. Goossens, M. and G. Plomteux, Inventaris van het cultuurbezit in België, Architectuur, Stad Antwerpen. Bouwen door de eeuwen heen. Brepols, Turnhout, 1976.

30. Onroerenderfgoeddecreet (Decree for cultural heritage), 2013. 